\title{
Plural de métodos, plural de tradiciones
}

\author{
Carlos Pereda
}

$\mathrm{E}$

n su trabajo "La relevancia del pensamiento de Gadamer en la filosofía: más allá de la modernidad y la posmodernidad", ${ }^{1}$ Ambrosio Velasco destaca, entre las principales contribuciones gadamerianas, la crítica a la confianza en "el método" para justificar nuestras creencias y acciones y la rehabilitación del concepto de tradición, un concepto que la Ilustración cubrió con inmenso descrédito.

En algún sentido ambos aportes conforman las dos caras de la misma medalla: el concepto moderno de método quiso ofrecernos un punto cero, una tabula rasa, a partir del cual podríamos comenzar y proseguir en la búsqueda del saber, sin enredarnos en el laberinto de los prejuicios y las circunstancias, trama que, precisamente, constituye toda tradición concreta. El método, pues, como un instrumento para exiliarse del sustento tradicional o, para usar la feliz expresión de Quine, como el pasaporte para un "exilio cósmico".

Tiene razón Ambrosio Velasco en subrayar la importancia de ambas contribuciones y sus diversos vínculos con otros debates de la filosofía contemporánea en apariencia, al menos, muy alejados de la hermenéutica como la filosofía de la ciencia pospositivista. En estas brevísimas notas quiero, sin embargo, discutir cierta peligrosa ambigüedad que recorre la crítica a las metodolatrías y el renacimiento del concepto de tradición.

Sin duda, ha sido de gran pertinencia todo el ataque contemporáneo a las modernas ilusiones del "método": a la insistente metodolatría que recorre el pensamiento moderno desde Bacon y Descartes hasta los neopositivistas y Popper. Pues indudablemente no existe tal cosa como un conjunto de reglas acontextuales o un criterio preciso, fijo y general para inventar o justificar

${ }^{1}$ Ambrosio Velasco, "La relevancia del pensamiento de Gadamer en la filosofía: más allá de la modernidad y la posmodernidad", en Revista del Colegio de Filosofía. Theoría, núm. 7. México, unAM, Facultad de Filosofía y Letras, diciembre, 1998, pp. 55-66. 
creencias, teorías y acciones. No obstante, debemos cuidarnos de no contraponer al fetiche de la metodolatría otro fetiche, la metodofobia. Porque si bien no existe tal cosa como "el método", sí hay diversos métodos: técnicas probadísimas que nos permiten alcanzar de forma muy confiable ciertas metas. Más acá de la reflexión filosófica, la observación del comportamiento de los científicos, sobre todo de los científicos naturales, permite de inmediato reconocer que una manera de socializarse en una ciencia y de llevar a cabo sus tareas más cotidianas consiste en actuar de acuerdo con ciertas técnicas probadas. Si no tenemos en cuenta la presencia de esas técnicas, una y otra vez obedecidas, con dificultad podremos entender el éxito de las ciencias, en especial, repito, el de las ciencias naturales (lo que Kuhn llamaba la "ciencia normal"). Y, desde esta perspectiva, saca de nuevo la cabeza el rostro del sujeto trascendental, o cuasi-trascendental, como sujeto de las ciencias naturales, construcción efectiva que abstrae de los sujetos históricos y socialmente arraigados. Sospecho que el pensamiento hermenéutico en su razonable crítica al "método" tiende a ocultar el precioso entramado de los "métodos" que conforma la realidad de cualquier laboratorio, y de virtudes epistémicas como la de la verificabilidad/refutabilidad empíricas.

Un vértigo simplificador paralelo lo encontramos en la tarea de rehabilitar la tradición. Ambrosio Velasco observa: "El acontecer de la tradición a través de la comprensión no puede ser controlable por metodología alguna, pues se trata del proceso mismo del desarrollo del hombre y de su contexto cultural, proceso que precede a toda manipulación metodológica por parte del sujeto". ${ }^{2}$

Me parece que pasajes como éste de Velasco conducen con facilidad al fetiche de concebir la tradición, por decirlo así, sin "pecado original": de pensar la tradición como se le piensa desde esa posición que designa la palabra de desmesura, "tradicionalismo" (que es, como se sabe, como pensar el alcohol como lo piensa el alcohólico). Las tradiciones no acontecen como cae la lluvia; en parte se construyen. De esta manera, a la vez que se sucumbe en el vértigo simplificador, se abraza también el vértigo de lo sublime: se piensa en una tradición más allá de toda manipulación, de toda estrategia, de todo interés por tener ésta y no otra tradición, en fin, la tradición como una de las tantas versiones del Mito de lo Dado.

Pero ello es una profunda distorsión, producto del peor vértigo de lo sublime, reitero. Respecto de cualquier tradición efectiva es posible detectar cómo ha sido construida y deformada, con qué intereses declarados o cubiertos se ha elegido este pasado en contra de otros pasados alternativos, por qué

${ }^{2}$ Ibid., p. 61. 
cierto canon rige esta tradición y no otro. En El ogro filantrópico, Octavio Paz ha observado cómo la tradición mexicana se ha generado a partir de sucesivas falsificaciones históricas acompañadas de célebres quemas de documentos:

El primer ejemplo mexicano de falsificación histórica es el de Izcoátl que, aconsejado por Tlacaélel, consejero del Tlatoani, ordenó la destrucción de los códices y las antigüedades toltecas, con el objeto de "rectificar la historia" en favor de las pretensiones aztecas. Sobre esta mentira se edificó la teología política de los mexicas. A esta mentira inicial han sucedido otras y todas animadas por el mismo propósito: la justificación del dominio político de este o aquel grupo. Nueva España comienza con dos quemas célebres, ambas obra de dos obispos que eran, significativamente, dos intelectuales, dos ideólogos: Juan de Zumárraga y Diego de Landa. Uno ordenó la destrucción de los códices y antigüedades de los mexicanos y otro la de los mayas. ${ }^{3}$

Las observaciones de Paz pueden generalizarse a cualquier tradición. Porque no hay tradición que, a la vez que construido documento de cultura, no haya sido también construido documento de barbarie, como ha dictaminado Walter Benjamin. De esta manera, recobra su fuerza la polémica de la Ilustración en contra de las tradiciones: no es posible enfrentarse a la tradición sin crítica ilustrada.

Debemos, pues, cuidarnos de no embarcarnos en el columpio de corregir un error con otro: ni cientificistas metodolatrías ni hermenéuticas metodofobias. También: ni ilustrada tabula rasa ni hermenéuticos tradicionalismos.

${ }^{3}$ Octavio Paz, El ogro filantrópico. México, Joaquín Mortiz, 1979, pp. 11-12. 